\title{
Disaster Planning for Homeless Populations: Analysis and Recommendations for Communities
}

\author{
Stephen C. Morris, MD, MPH
}

Assistant Professor of Emergency Medicine and Public Health, University of Washington, Seattle, Washington USA

Correspondence:

Stephen C. Morris, MD, MPH

Assistant Professor of Emergency Medicine and Public Health

University of Washington

$3259^{\text {th }}$ Avenue, Seattle, Washington 98104 USA

E-mails: scmorris@uw.edu;

stephenmorrismd@gmail.com

Conflicts of interest: none

Keywords: disaster planning; homelessness; populations; vulnerable

Received: June 16, 2019

Revised: October 5, 2019

Accepted: October 27, 2019

doi:10.1017/S1049023X20000278

(C) World Association for Disaster and

Emergency Medicine 2020.

\begin{abstract}
Homelessness is a growing problem, with perhaps greater than a 150 million homeless people globally. The global community has prioritized the problem, as eradicating homelessness is one of the United Nation's sustainability goals of 2030. Homelessness is a variable entity with individual, population, cultural, and regional characteristics complicating emergency preparedness. Overall, there are many factors that make homeless individuals and populations more vulnerable to disasters. These include, but are not limited to: shelter concerns, transportation, acute and chronic financial and material resource constraints, mental and physical health concerns, violence, and substance abuse. As such, homeless population classification as a special or vulnerable population with regard to disaster planning is well-accepted. Much work has been done regarding best practices of accounting for and accommodating special populations in all aspects of disaster management. Utilizing what is understood of homeless populations and emergency management for special populations, a review of disaster planning with recommendations for communities was conducted. Much of the literature on this subject generates from urban homeless in the United States, but it is assumed that some lessons learned and guidance will be translatable to other communities and settings.
\end{abstract}

Morris SC. Disaster planning for homeless populations: analysis and recommendations for communities. Prehosp Disaster Med. 2020;35(3):322-325.

\section{Introduction}

The United States, like many other countries, has an increasing number of homeless individuals and families. Extensive effort has been put toward avoiding homelessness, providing shelter and services to the homeless, as well as providing avenues and access to transitional and permanent housing. Efforts have also been made to address the many causes of people becoming homeless, such as poverty reduction and housing rights legislation. Despite these efforts, the number of homeless individuals was estimated at 550,000 in 2018 by the US Department of Housing and Urban Development (Washington, DC USA). ${ }^{1}$

There is much diversity within homeless populations in the United States. Homeless disabled people, children, and families are of special interest to service providers and policy makers. While definitions of these groups vary, there is accord on general demographics and trends. Those with disabilities have been estimated to make up $40 \%$ of the homeless population, versus approximately $18 \%$ of the general population. ${ }^{2}$ In 2018 , one-third of all homeless people were part of a family with children, with over one-half of these being the children themselves. This means there were approximately 100,000 homeless children in the United States in 2018. ${ }^{1}$

Report

Defining Vulnerability of Homeless Populations with Regards to Disasters

The Federal Emergency Management Agency (Washington, DC USA) defines vulnerable populations with regard to disasters as:

Populations whose members may have additional needs before, during, and after an incident in functional areas, including but not limited to: maintaining independence, communication, transportation, supervision, and medical care. Individuals in need of additional response assistance may include those who have disabilities; who live in institutionalized settings; who are elderly; who are children; who are from diverse cultures; who have limited English proficiency; or who are non-English speaking; or who are transportation disadvantaged. ${ }^{3}$ 
Meeting this definition, many factors make homeless individuals and populations more vulnerable to disasters, including: the capacity to be personally prepared, access to information and transportation, special medical and mental health needs, as well as dependence on and complex relationship with social services and governance, to name a few. Describing disaster-related attributions of these populations provides insight into the nature of the vulnerability.

\section{Medical and Mental Health Needs}

Homeless populations have different health needs, patterns of health care utilization, and health outcomes than the general population. ${ }^{4}$ In particular, there are higher rates of domestic violence, mental health needs, and substance abuse, all with associated health concerns. Additionally, homelessness itself may be a marker of immunosuppression and associated increased risk of infection. ${ }^{5}$ Homeless populations may also have greater chronic health needs, such as those receiving daily methadone and directly observed therapy for tuberculosis.

Despite these increased health needs, access to and utilization of health care services remains less than ideal. ${ }^{6,7}$ While overall access to care remains inadequate, high rates of health care utilization and emergency services recidivism are seen among some homeless individuals. This use of emergency services represents a burden to the health care system, resulting in bias towards homeless individuals, further exacerbating substandard care. ${ }^{8}$

While the exact measurement of mental health and substance abuse needs among homeless population varies, studies nearly universally demonstrate higher rates than the general population. A meta-analysis of studies from seven European and North American studies demonstrated high estimates of prevalence of alcohol and drug dependence (59\% and 54\%, respectively), as well as psychotic disorders and major depression (both approximately 40\%). ${ }^{9}$ Another literature review demonstrated clear consensus on the nature and extent of the burden of mental health and substance abuse in this population, despite variability in the populations and study methods. ${ }^{10}$

\section{Information and Preparedness}

Additionally, those who are homeless often lack the ability to respond to public recommendations before and during a disaster. Common recommendations, such as voluntary evacuation and stockpiling of food, water, medicines, and supplies, may be beyond the abilities and resources of homeless individuals and families. It is established that homeless populations may not have access to mainstream messaging regarding disasters, and therefore, are at-risk of being caught unawares. ${ }^{11}$

\section{Relationship with Social Services and Government Entities}

Homeless populations may be reliant on services that are easily disrupted in the setting of disasters as governments and social service organizations are forced to re-prioritize. Homeless populations may also be very dependent on social services and the public transportation required to get to these services. The link between location, public transportation, and social services is vital to survival for homeless populations and is vulnerable to disruption. This link must also be re-created in the setting of post-disaster recovery.

Homeless undocumented individuals, those with on-going criminal activities or record, and those with a general fear of authority may be hesitant to participate in disaster activities perceived as increasing their visibility to law enforcement.

\section{Shelter}

Many areas previously occupied by homeless populations may no longer be accessible or appropriate following a disaster. Many public spaces and resources previously assigned to homeless populations may be reallocated for the general population after a disaster. There have been incidents of immoral exclusion of homeless individuals from shelters, as well as unsupported allegations of abuse by homeless individuals in disaster shelters, lending a complexity to the recommendations in this area. ${ }^{12}$ Additionally, the use of specialized shelters contradicts the inclusive nature of disaster planning for vulnerable populations. Regarding shelter locations, the link between services and shelter areas, one that is vital for those dependent on the services, may be broken following a disaster. The disaster event may also increase long-term homelessness as the link between emergency, transitional, and permanent housing following a disaster and the creation of homelessness is well-established. ${ }^{13}$ Competition for limited resources following disaster events between new and old homeless populations creates its own logistical, ethical, and political challenges. ${ }^{14}$

\section{Discussion}

\section{Disaster Planning for Homeless Individuals and Populations}

Guidance for communities and civil society groups working with homeless populations exist, and while supported by data, many of these guides are written from expert consensus. ${ }^{15}$ Additional insight comes from attempts at qualitative assessment of the field. ${ }^{16,17}$ Guidance including government guidelines and civil service group's guidelines highlight the special needs of this populations, anticipation of needs in emergency settings, and mechanisms for appropriate planning and intervention. Paramount in these recommendations is the inclusion of the many government and civil service organizations working with homeless populations into the disaster planning process. Additionally, interpretation of guidance to communities should account for the profound variability of both homeless population's characteristics and needs, as well as disaster planning and response. Therefore, communities will need to adapt recommendations to their local environment for maximum benefit.

\section{Planning Integration}

Those with special needs, such as the homeless, should be integrated into the general planning and service provision as much as possible. This core tenant of special needs service provision is well-supported in disaster planning. ${ }^{18}$ Within this ideal is the concept of functional needs, which are those items or actions that allow individuals to maintain independence, autonomy, and dignity regardless of their functional status. ${ }^{19}$ These concepts fit into the overall model of "community resilience development" as a major tenant of disaster planning. ${ }^{20}$

\section{Medical and Mental Health Needs}

Community health care institutions that focus on under-served individuals during normal operations, such as mission-driven institutions and health care for the homeless organizations, offer an opportunity for disaster-related outreach. It is expected that these organizations will play a key role in service provision during a disaster and the recovery, as highlighted by this quote from the US Department of Health and Human Services (Washington, DC USA): "Health centers are positioned to play an important role in delivering critical services and assisting local communities during an emergency." ${ }^{21}$ However, health centers as a whole are not wellintegrated into community disaster planning and preparedness. ${ }^{22}$ 
Special resources are likely to be needed with regard to homeless populations with mental health and substance abuse history and dependence. It is likely this population will have a disruption in their access to care and access to the illicit intoxicants to which they are dependent, as well as decompensation as a result of the emotional context of the disaster event and social disruption. Special planning may be needed for individuals who regularly seek Emergency Medical Services, as these services are likely to be overwhelmed during disasters. Mental health psychological and disaster first aid courses are available and should be encouraged by disaster planners as these individuals may be particularly helpful with individuals profoundly affected by the event. ${ }^{23}$

\section{Communication}

Efforts should be made to overcome the challenges in accessing disaster information faced by homeless people. Outreach teams are necessary to circumvent lack of access to mainstream messaging. Caution should be used when messaging could be construed as authoritarian, risking further alienation of some individuals. Providing information at points of service access, such as food distribution, is an excellent avenue to disseminate and clarify information. Utilization of trained social service providers, combined with disaster experts, may also help in information being delivered in an interpretable and acceptable manner while focusing on critical, event-specific disaster components. An example of this is the Public Health-Seattle and King County's (Seattle, Washington USA) Vulnerable Populations Action Team (VPAT). This team seeks to "ensure that vulnerable populations have access to public health information and services about preparedness, response, and recovery. The team includes a diverse cross-section of staff with public health expertise in vulnerable populations, preparedness, and infectious diseases." ${ }^{24}$ Other models and strategies for outreach and communication exist and are available. ${ }^{25}$

\section{Materials Planning}

Personal and family supplies of food, water, medicines, and comfort items represent a core component of disaster preparedness.
However, these items may be out of reach for many homeless individuals and families. The first priority, given the established communication barriers these populations face, would be to ensure that the need for these items is anticipated using the communication strategies outlined above. Stockpiling of emergency supplies by service organizations already catering to these populations would provide a method of resource delivery in the event of a disaster. Caching and distribution of emergency kits to individuals and families is a more labor and resource intensive option. ${ }^{12}$ It is likely that these methods would also be required for many non-homeless affected by a disaster as well.

\section{Shelter}

Efforts to avoid new homelessness after a disaster, and provide permanent housing solutions to the previously homeless, should be a priority to disaster planners and policy makers. At its most basic level, shelter should meet minimum standards of security, hygiene, privacy, and comfort in the least restrictive manner possible, with an emphasis on keeping families together. ${ }^{26}$

\section{Conclusion}

Planning for and supporting vulnerable populations is not only a moral imperative, it is likely to benefit the system as a whole by avoiding over-extension of systems and services not designed for the needs of special populations. However, much work in this area needs to be done regarding not only planning and education, but also awareness. This was exemplified when, during a disaster response, victims were excluded from services for the reason of being homeless prior to the disaster. Engagement of service providers who work with homeless populations into the disaster planning process is the most important over-arching recommendation. Community and specialized disaster planners, such as those in the health care community, should attempt to understand the needs of these individuals and strive to incorporate planning for them into their comprehensive, all-hazards disaster plans.

\section{References}

1. US Department of Housing and Urban Development. The 2018 Annual Homeless Assessment Report (AHAR) to Congress. https://files.hudexchange.info/resources/ documents/2018-AHAR-Part-1.pdf. Accessed September 30, 2019.

2. Diament M. More Than Two-Fifths of Homeless Have Disabilities. Disabilityscoop: The Premier Source for Developmental Disability News. July 2009. https://www. disabilityscoop.com/2009/07/16/homeless-report/4153/. Accessed September 30, 2019.

3. Federal Emergency Management Agency and 19 DHS Office for Civil Rights and Civil Liberties. Interim Emergency Management Planning Guide for Special Needs Populations. August 2008. http://www2.ku.edu/ rrtcpbs/resources/pdf/ FEMA_CPG301.pdf. Accessed September 1, 2019.

4. Fazel S, Geddes JR, Kushel M. The health of homeless people in high-income countries: descriptive epidemiology, health consequences, and clinical and policy recommendations. Lancet. 2014;384(9953):1529-1540.

5. Rimawi BH, Mirdamadi M, John JF. Infections and homelessness: risks of increased infectious diseases in displaced women. World Medical E Health Policy. 2014;6(2): 118-132.

6. Baggett TP, O'Connell JJ, Singer DE, Rigotti NA. The unmet health care needs of homeless adults: a national study. Am J Public Health. 2010;100(7):1326-1333.

7. Canavan R, Barry MM, Matanov A, et al. Service provision and barriers to care for homeless people with mental health problems across 14 European capital cities. BMC Health Serv Res. 2012;12:122.

8. Lam CN, Arora S, Menchine M. Increased 30-day emergency department revisits among homeless patients with mental health conditions. West J Emerg Med. 2016;17(5):607-612.

9. Fazel S, Khosla V, Doll H, Geddes J. The prevalence of mental disorders among the homeless in western countries: systematic review and meta-regression analysis. PLoS Med. 2008;5(12):e225.

10. Fischer PJ, Breakey WR. The epidemiology of alcohol, drug, and mental disorders among homeless persons. American Psychologist. 1991;46(11):1115-1128.

11. US Department of Housing and Urban Development. HUD Exchange: Disaster Recovery Homelessness Toolkit. https://www.hudexchange.info/news/disasterrecovery-homelessness-toolkit-recovery-guide-for-local-jurisdictions-now-available/. Accessed October 3, 2019.

12. Edgington S. Disaster Planning for People Experiencing Homelessness National Health Care for the Homeless Council March 2009. http://www.nhchc.org/wp-content/ uploads/2011/10/Disaster-Planning-for-People-Experiencing-Homelessness.pdf. Accessed September 30, 2019.

13. International Displacement Monitoring Centre. Global Disaster Displacement Risk - A Baseline for Future Work. Published October 2017. http://www.internaldisplacement.org/publications/global-disaster-displacement-risk-a-baseline-for-futurework. Accessed September 30, 2019.

14. Levine A. After a California Wildfire, New and Old Homeless Populations Collide. New York Times. Published December 3, 2018. https://www.nytimes.com/2018/12/ 03/us/california-fire-homeless.html. Accessed September 30, 2019.

15. Wexler B, Smith ME. Disaster response and people experiencing homelessness: addressing challenges of a population with limited resources. J Emerg Manage. 2015;13(3):195-200.

16. Fogel SJ. Reducing vulnerability for those who are homeless during natural disasters. Journal of Poverty. 2017;21(3):208-226.

17. Gin JL. Disaster preparedness in homeless residential organizations in Los Angeles County: identifying needs, assessing gaps. Natural Hazards Review. 2016; 17(1).

18. US Department of Homeland Security, Federal Emergency Management Agency. Guidance on Planning for Integration of Functional Needs Support Services in 
General Population Shelters. November 2010. https://www.fema.gov/media-librarydata/20130726-1831-25045-7316/fnss_guidance.pdf. Accessed September 30, 2019.

19. Kailes J, Enders A. Moving beyond 'special needs:' a function-based framework for emergency management planning. Journal of Disability Policy Studies. 2007;44:230-237.

20. Plough A, Fielding JE, Chandra A, et al. Building community disaster resilience: perspectives from a large urban county department of public health. Am J Public Health. 2013;103(7):1190-1197.

21. Health Resources and Service Administration, US Department of Health and Human Services. Health Center Emergency Management Program Expectations. Published 2007. https://bphc.hrsa.gov/sites/default/files/bphc/about/pdf/pin200715.pdf. Accessed September 30, 2019.

22. Wineman NV, Braun BI, Barbera JA, Loeb JM. Assessing the integration of health center and community emergency preparedness and response planning. Disaster Med Public Health Prep. 2007;1(2):96-105.
23. National Association of Social Workers. Certified Disaster Mental Health Responder. Online Course. https://www.nasw-md.org/page/112. Accessed September 30, 2019.

24. Public Health-Seattle and King County (WA) Vulnerable Populations Action Team (VPAT) Standards. https://www.kingcounty.gov/depts/health/emergency-preparedness/ partnerships/Community-Resilience-Equity-Program/ /media/depts/health/emergencypreparedness/documents/VPAT-standards.ashx. Accessed September 30, 2019.

25. Klaiman T. Locating and communicating with at-risk populations about emergency preparedness: the vulnerable populations outreach model. Disaster Med Public Health Prep. 2010;4(3):246-251.

26. US Department of Housing and Urban Development. ESG Minimum Habitability Standards for Emergency Shelters and Permanent Housing. Resources and Assistant to Support HUD's Community Partners. https://files.hudexchange.info/ resources/documents/ESG-Emergency-Shelter-and-Permanent-Housing-Standards. pdf. Accessed September 30, 2019. 